\title{
Review Article \\ Glucosamine for Osteoarthritis: Biological Effects, Clinical Efficacy, and Safety on Glucose Metabolism
}

\author{
Juan Salazar, ${ }^{1}$ Luis Bello, ${ }^{1}$ Mervin Chávez, ${ }^{1}$ Roberto Añez, ${ }^{1}$ \\ Joselyn Rojas, ${ }^{1,2}$ and Valmore Bermúdez ${ }^{1}$ \\ ${ }^{1}$ Endocrine and Metabolic Diseases Research Center, Faculty of Medicine, University of Zulia, \\ Maracaibo 4004, Venezuela \\ ${ }^{2}$ Institute of Clinical Immunology, University of Los Andes, Mérida 5101, Venezuela \\ Correspondence should be addressed to Valmore Bermúdez; vbermudez@hotmail.com
}

Received 29 September 2013; Accepted 20 December 2013; Published 11 February 2014

Academic Editor: Jiri Vencovsky

Copyright (C) 2014 Juan Salazar et al. This is an open access article distributed under the Creative Commons Attribution License, which permits unrestricted use, distribution, and reproduction in any medium, provided the original work is properly cited.

\begin{abstract}
Osteoarthritis is a chronic degenerative disorder that currently represents one of the main causes of disability within the elderly population and an important presenting complaint overall. The pathophysiologic basis of osteoarthritis entails a complex group of interactions among biochemical and mechanical factors that have been better characterized in light of a recent spike in research on the subject. This has led to an ongoing search for ideal therapeutic management schemes for these patients, where glucosamine is one of the most frequently used alternatives worldwide due to their chondroprotective properties and their long-term effects. Its use in the treatment of osteoarthritis is well established; yet despite being considered effective by many research groups, controversy surrounds their true effectiveness. This situation stems from several methodological aspects which hinder appropriate data analysis and comparison in this context, particularly regarding objectives and target variables. Similar difficulties surround the assessment of the potential ability of glucosamine formulations to alter glucose metabolism. Nevertheless, evidence supporting diabetogenesis by glucosamine remains scarce in humans, and to date, this association should be considered only a theoretical possibility.
\end{abstract}

\section{Introduction}

Osteoarticular disease currently represents one of the most common presenting complaints in clinical practice, generating severe impacts in the quality of life of patients and representing a heavy economic burden for public health systems [1]. Within this group, osteoarthritis (OA) is the most prevalent articular disorder, with a prevalence of up to $80 \%$ in subjects over 65 years of age [2]. Nevertheless, variability in diagnostic criteria, variations of methodology in epidemiologic studies, and a relative scarcity of research in the subject have obscured the true scope of this issue [3].

Venezuela does not escape this scenario. As described in epidemiologic reports by the National Center of Rheumatic Disease during the 1995-2010 period, OA is the third osteoarticular disorder most frequently diagnosed at first consultation, representing $16,22 \%(n=13,983)$ [4]. Still, said report does not specify whether these figures include diagnoses made in primary attention consultations, which should ideally detect most of these patients.

OA, also called osteoarthrosis, is a chronic arthropathy characterized by the degeneration and loss of articular cartilage, resulting in disruption of its mechanical properties and those of subchondral bone as well as modifications in the surrounding soft tissue. Although this process can develop in all osteoarticular structures, the knee remains the most accessibly assessed and the one with the most specific evaluation criteria $[3,5]$. Nonmodifiable risk factors associated with $\mathrm{OA}$ include advanced age, female gender, and ethnicity; while articular overload, intense physical activity, and obesity are modifiable risk factors. Altogether, these components must all be included in the integral management of this kind of patients [5].

Currently recognized pathophysiologic mechanisms involve not only articular lesion and degeneration but also a coexisting chronic inflammatory process which favors 
the progressive loss of hyaline cartilage through numerous molecular mediators [6]. Furthermore, chondral structures may not be the sole target of this deterioration, since all components of the articular surface seem to be affected [7]. In recent times, this paradigm shift has led to an ongoing review of therapeutic management schemes for these patients, wherein glucosamine supplements remain cornerstone prescriptions in clinical practice, both by primary attention of physicians and specialists [8]. Nevertheless, their biochemical features and implications render it necessary to delve further into their repercussions over carbohydrate metabolism, considering the array of endocrine-metabolic adverse effects they have been linked to.

\section{Pathophysiology of Osteoarthritis}

Despite the great prevalence and impact of OA in the adult population, its specific etiology remains unknown; and much like most chronic diseases, a constellation of risk factors have been proposed to interact amongst each other in this case, both biochemically and mechanically, ultimately leading to the onset and progression of this disease [9]. Articular cartilage, a fundamental component of the osteoarticular system, is the main degradation target, yet other structures are also affected including subchondral, capsular, synovial, and periarticular soft tissue $[10,11]$. Still, the principal disruption occurs within the chondrocyte, with an unbalance between the synthesis and degradation of extracellular matrix, because of an excessive local release of proteolytic enzymes, and a progressive deceleration of cartilage reparation $[12,13]$.

In addition, a vast catalogue of bioactive molecules is synthesized at the chondral level, including proinflammatory cytokines IL-1, IL-8, IL-17, IL-18, and TNF- $\alpha$, as well as free radicals (nitric oxide), growth factors (TGF- $\beta$ ), and lipidic mediators (Prostaglandin $\mathrm{E}_{2}$, Leukotriene $\mathrm{B}_{4}$ ) [14]. This inflammatory component develops primarily at the synovial membrane, coexisting with other degenerative mechanisms, and has led research efforts to contemplate therapeutic interventions directed to the stimulation of cartilage synthesis, modulation of inflammation, and regulation of chondrocyte metabolism $[6,15]$.

Notably, Aspden et al. [16] have suggested considering $\mathrm{OA}$ as a systemic disease, where the main disruption would involve lipid metabolism and stromal cell differentiation, a concept stemmed from the common embryologic origin shared by all structures constituting the articular cavity. Nonetheless, current views remain focused on the local pathology, where novel pathophysiologic pathways and factors are constantly discovered, generating potential therapeutic targets [17]; Figure 1 depicts the main pathophysiologic routes of $\mathrm{OA}$.

\section{Therapeutic Management of Osteoarthritis}

Along with pharmacologic agents, nonpharmacologic measures remain a cornerstone of OA treatment, fundamentally, the management of all risk factors involved and possible comorbidities such as obesity, diabetes, and menopause [18].
Therefore, patient education, physical activity, physiotherapy, articular protection, postural hygiene, and weight control are essential injury- and pain-limiting tools, which are generally included in all clinical guidelines for the integral management of OA patients, albeit receiving varying degrees of recommendation throughout different regions worldwide $[5,18-$ 21].

On the other hand, the main objective of drug use in $\mathrm{OA}$ is symptomatic management, reducing both pain and underlying inflammation [22]. Various management guidelines have categorized these drugs as Symptom Modifying Osteoarthritis Drugs (SMOADS) $[23,24]$ which are divided into 2 subgroups:

(i) rapid-acting drugs including analgesics, nonsteroidal anti-inflammatory drugs (NSAIDs), and intraarticular glucocorticoids and opioids;

(ii) slow-acting drugs or SYSADOA (Symptomatic Slow Acting Drugs for Osteoarthritis).

Regarding the first subgroup, paracetamol is considered the initial drug for the management of knee OA $[25,26]$, with NSAIDs being broadly recommended if no satisfactory results are observed after first-line management, although their adverse effect profiles should be considered prior to prescription [27, 28]. Lastly, intra-articular opioids and glucocorticoids are only implemented in very specific situations where initial treatment has been inefficient [19]. In general, utilization of drugs in this subgroup depends on their safety profile, patient consent, cost-effectiveness, and other factors relevant to the specific clinical evolution of patients $[5,23]$.

Findings reported in the 90s decade about articular cartilage, its metabolic activity, and regenerative capacity [29, 30] have led to the proposal of chondromodulating and/or chondroprotective substances, which constitute the group of slow-acting drugs or SYSADOA, including cartilaginous matrix precursors (glucosamine, chondroitin, and hyaluronic acid) and cytokine modulators (diacerein and metalloprotease inhibitors) [24]. These drugs, particularly glucosamine (GluN), have raised controversy regarding their utilization, due to inconsistencies in findings on their effectiveness in the treatment of these patients $[19,31,32]$. Figure 2 summarizes the therapeutic management of OA patients.

\section{What Is Glucosamine? Molecular Aspects}

GluN (2-amino-2-deoxy-D-glucose) is an aminomonosaccharide derived principally from chitin, a compound found in the exoskeleton of certain marine invertebrates [33]. GluN is an essential noncellular component of connective tissue, cartilage, ligaments, and other structures $[24,34]$ (Figure 3). The main compounds including GluN are glucosamine hydrochloride, glucosamine sulfate, and $\mathrm{N}$-acetylglucosamine [34]. The latter can be organically synthesized through the hexosamine pathway, an alternative metabolic route to glycolysis, which is esteemed to consume up to $5 \%$ of glucose in adipocyte cultures [35].

This metabolic pathway is essential for the biosynthesis of amino sugars, utilizing fructose-6-phosphate and glutamine 


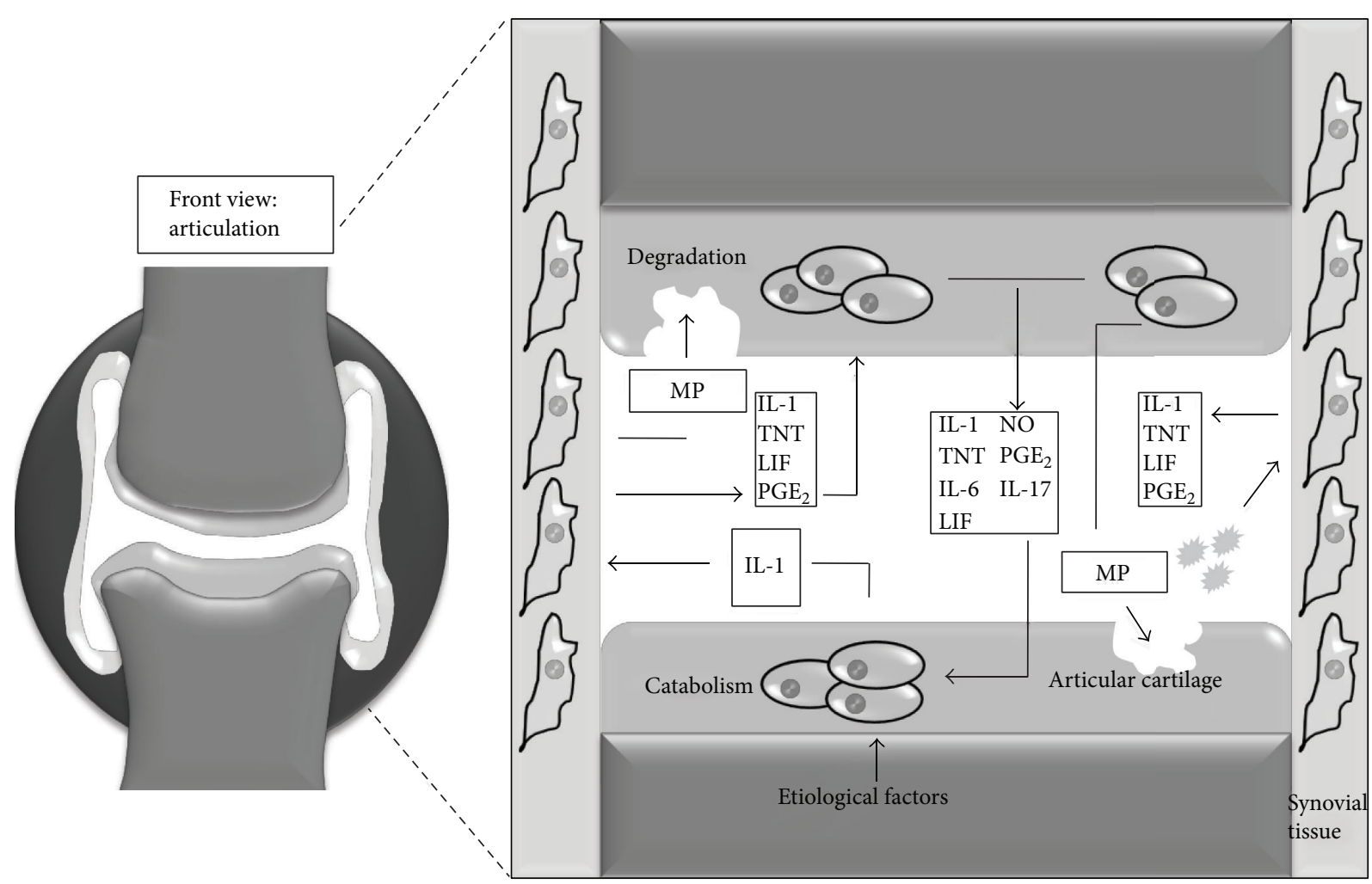

FIgURE 1: Physiopathology of osteoarthritis. IL: interleukin; TNF: tumoral necrosis factor; NO: nitric oxide; PG: prostaglandins; MP: metalloproteases; LIF: leukemia inhibitory factor. Targets of diverse pathophysiologic factors of osteoarthritis include not only articular cartilage but also several structures of the articular surface, where an unbalance favoring catabolism occurs, with degradation of extracellular matrix. This process is triggered by numerous proinflammatory and proteolytic molecules which generate a local vicious circle. (Refer to text.)

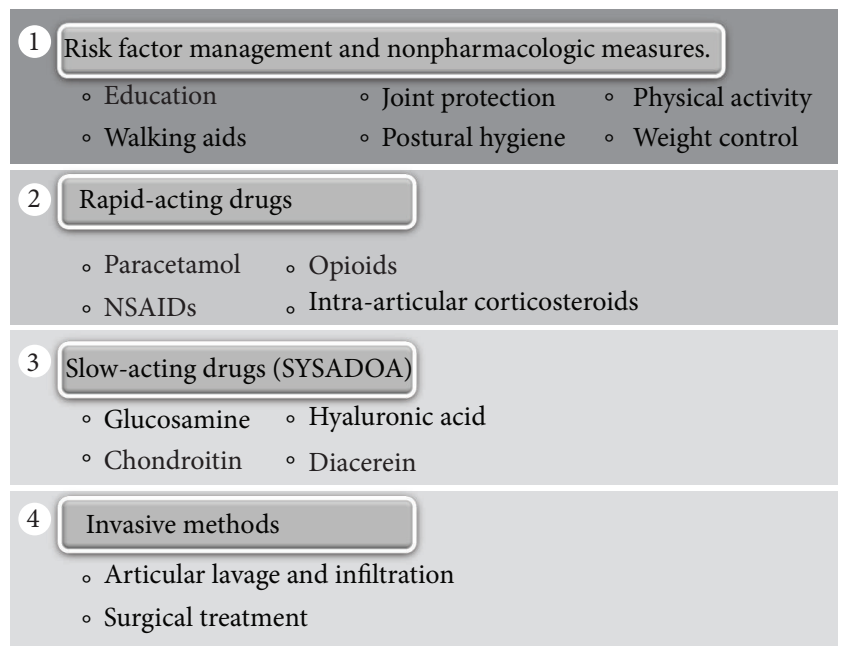

Figure 2: Possible interventions in therapeutic management of Osteoarthritis.

(as an amino-group donor) to produce glucosamine6-phosphate (GluN-6-P), catalyzed by the enzyme glutamine:fructose 6-phosphate amidotransferase (GFAT), which represents the rate-limiting step in this process $[36,37]$.
Besides this "endogenous" production, glucosamine provided exogenously can be introduced to cells through glucose transporters (especially GLUT-2), and phosphorylated intracellularly by hexokinase to GluN-6-P, avoiding the ratelimiting reaction of the aforementioned pathway [38, 39]. The next step is the acetylation of GluN-6-P to N-acetylglucosamine 6-phosphate (N-Acetyil-GluN-6-P), catalyzed by glucosamine-phosphate- $\mathrm{N}$-acetyltransferase. Then, this compound is transformed into uridine-5-diphosphate- $\mathrm{N}$ acetyl-glucosamine (UDP-N-Acetyl-GluN) by the enzyme UDP-N-acetyl-glucosamine pyrophosphorylase. UDP$\mathrm{N}$-Acetyl-GluN is the precursor for the biosynthesis of amino sugars which serve as building blocks for GAGs, proteoglycans, and glycoproteins, by transferring $\beta-\mathrm{N}$ acetyl-glucosamine to the hydroxyl groups of serine and/or threonine residues of a broad span of proteins [34, 40, 41]. Lastly, UDP-N-Acetyl-GluN can be converted to UDP-Nacetyl-galactosamine through isomerization mediated by the enzyme N-acetyl-glucosamine-4-epimerase [37].

This succession of reactions is followed by posttranslational proteic modifications, which have been related to various biological processes, especially those regulating the metabolism of carbohydrates and insulin sensitivity, associated with glucotoxicity and insulin resistance (IR) [42]. Thus, the hexosamine pathway has been proposed to be more 


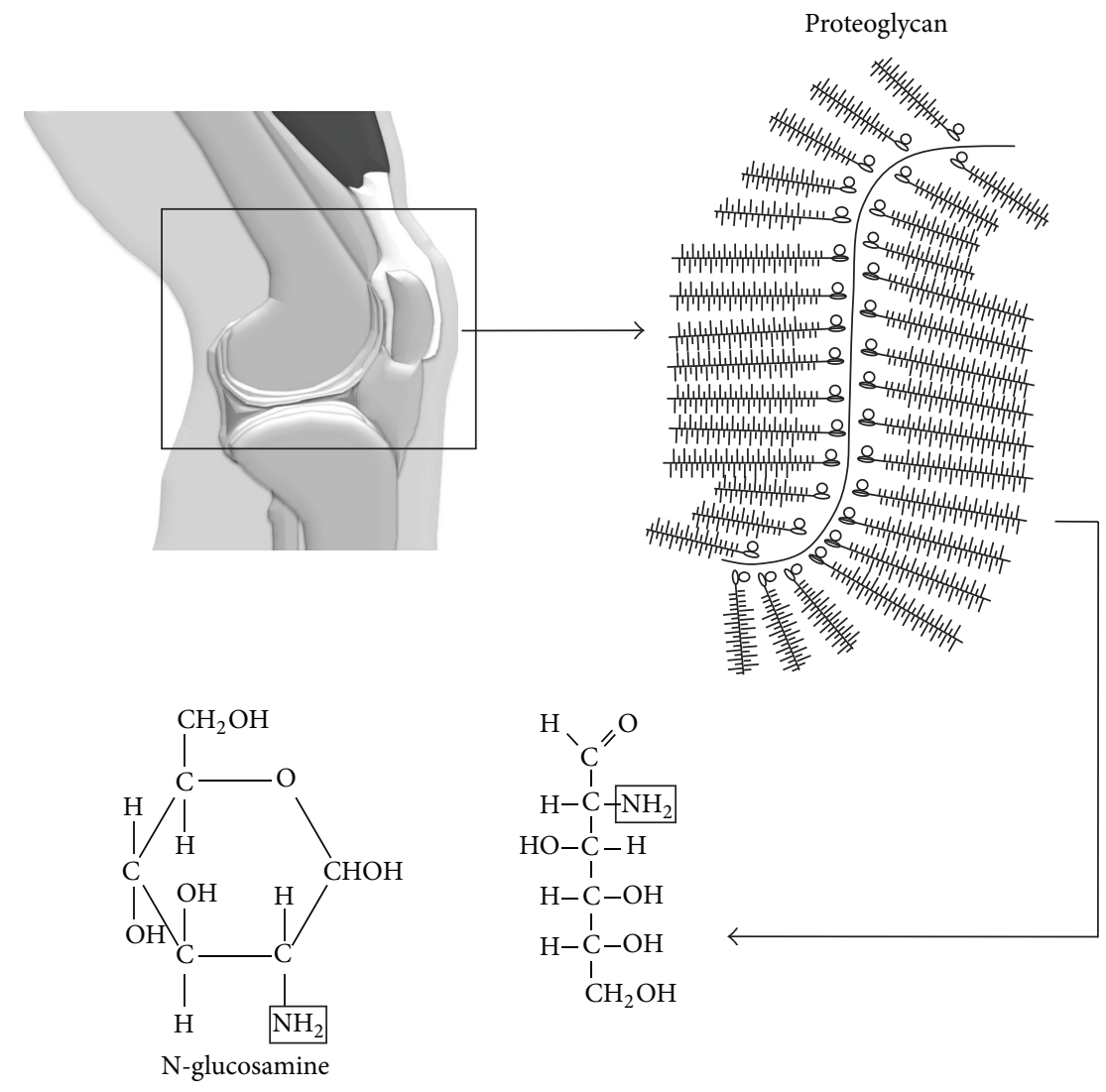

Figure 3: Chemical structure of glucosamine.

than a simple glucosensor, as it may be a potential mediator implicated in the pathogenesis of Type 2 Diabetes Mellitus (T2DM) $[35,43]$. The main reactions in the hexosamine pathway are shown in Figure 4.

The rate-limiting step in the regulation of this route involves GFAT, which is the only ammonium-independent enzyme of the amidotransferase subfamily [44]. It is also strongly inhibited by the final product of this metabolic pathway (UDP-N-Acetyl-GluN) through an allosteric mechanism [45]. Therefore, its activity is influenced by UDP-NAcetyl-GluN intracellular concentrations and intensified by Protein Kinase A (PKA)-dependent phosphorylation [46, 47]. Moreover, its affinity for fructose-6-phosphate is low, so the concentration of this substrate plays an important role in the start-up of this reaction [40].

Ultimately, the plasmatic concentration of glucosamine in healthy subjects is approximately $0.04 \mathrm{mmol} / \mathrm{L}$, rising up to $0.06 \mathrm{mmol} / \mathrm{L}$ in those taking common doses of glucosamine supplements $[34,48]$. It should be noted that the oral route offers only $20 \%$ the plasmatic concentrations which would be obtained through intravenous administration $[34,49,50]$. It has been suggested that the pharmacokinetics and pharmacodynamics of glucosamine in humans closely resemble those of experimental rat models [51].

\section{Glucosamine: Effective for Osteoarticular Disease?}

When evaluating the effectiveness of a drug or therapeutic tool, it is important to consider the target variables susceptible to modification or "end points," which in the case of clinical assays on patients with knee OA are represented mainly by pain and measurement of articular space [52]. Based on these and other manifestations, several indices or score systems have been created to allow researchers to assess the severity and evolution of the disease when under a given therapy [53, 54], The Western Ontario and McMaster Universities OA (WOMAC) index and the Lequesne functional severity index are some of the most frequently used across various clinical assays [52].

Another aspect worth considering when assessing effectiveness is the type of supplement prescribed; currently, glucosamine hydrochloride and sulfate are the most commercialized in our country and worldwide [55]. However, several studies have reported that when comparing both formulations, glucosamine sulfate exhibits more favorable results, especially in its crystalline form $[24,56,57]$. These differing formulations, as well as differences in pharmaceutical manufacturing, are responsible for distinct pharmacokinetic 


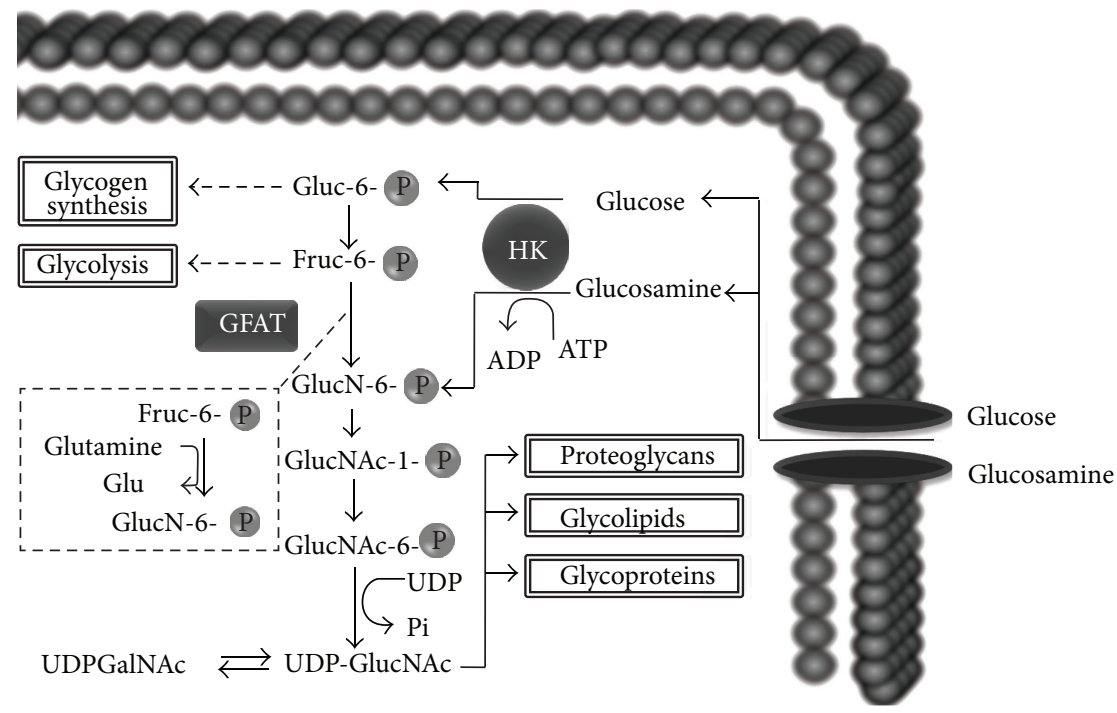

FIGURE 4: Glucosamine biosynthesis. HK: hexokinase; Gluc-6-P: glucose-6-phosphate; Fruc-6-P: fructose-6-phosphate; GFAT: glucosamine fructose-6-phosphate amindotransferase; GlucN-6-P: Glucosamine-6-phosphate; GlucNAc-6-P: N-acetyl-glucosamine-6-phosphate; GlucNAc-1-P: N-acetyl-glucosamine-1-phosphate; UDPGalNAc: uridine diphosphate (UDP)-N-acetyl-galactosamine; UDP-GlucNAc: UDP-N-acetyl-glucosamine. Glucosamine may be obtained from exogenous supplements, or it may be endogenously synthesized from glucose through the hexosamine pathway, an alternate pathway to glycolysis. Its product is uridine 5-diphosphate- $\mathrm{N}$-acetyl-glucosamine (UDP-N-Acetyl-GluN), which is a precursor for glycosaminoglycans, proteoglycans, and glycoproteins. (Refer to text.)

features which must be taken into consideration, as they could influence comparisons between reports [58].

Regarding dosages, although each presentation shows specific characteristics, therapeutic effects are obtained with doses ranging between 1,250-1,500 $\mathrm{mg}$ daily [59, 60]. As their name implies, SYSADOA offer a slow onset of reliefapproximately 2 weeks - and their effects may remain active for as long as 2 months after their omission [61]. Notably, the European Medicines Agency has suggested that at least 6 months of treatment are required for the evaluation of SYSADOA effectiveness for articular pain and 2 years are necessary to assess modifications of articular structures [58].

All elements considered a true overarching feature of research in the evaluation of these supplements as their overwhelming heterogeneity with respect to objectives, formulations, combinations with other compounds, and time of use, among many other variables of utmost importance when comparing studies. Indeed, the heterogeneity in outcome measures is particularly noteworthy and unjustified, considering most rheumatologic diseases have been discussed in OMERACT conferences, whose purpose is unification of evaluation criteria for clinical assays in this field [62]. Regarding OA, since OMERACT 3 in 1996, the 3 main aspects to be evaluated in all Phase III studies are pain, physical function, and global patient assessment, as per the simplified OARSI criteria in each of its scenarios and thus allowing for result unification and facilitating comparisons between studies. Only after considering these fundamental aspects can the novel variables in OA progression be considered [52].

This line of research ranges from clinical assays to meta-analyses, encompassing hundreds of patients (Table 1). Parallel studies by Reginster et al. and Pavelká et al. [63, 64] demonstrated the disease-modifying ability of glucosamine sulfate supplements, by ascertaining improvement of symptomatology and prevention of articular space loss in knee OA patients at a 3-year follow-up. Furthermore, results from a subsequent follow-up on these patients at an average of 5 years suggested that treatment with glucosamine sulfate for at least 12 months may prevent the need for knee arthroplasty, revealing the profound extent of the diseasemodifying power of this compound [65].

The effects in the short-medium term have been evaluated by studies such as the GUIDE Trial [66], which confirms previous reports regarding the significant improvement glucosamine sulfate yields on symptoms of knee OA, in the range or even superior to what exerted by a first line NSAID or acetaminophen.

Nevertheless, it must be noted that in other reports, benefits do not seem to be present in all analyzed subjects, but only in specific subgroups with distinctive clinical features. This has been exemplified by Clegg et al. [67], who after utilizing glucosamine hydrochloride in their study-a valuable methodological aspect for the comparison of results [58] could not prove this version of the supplement to reduce pain after 24 weeks in knee OA patients with mild articular pain. These variations in the utilized supplements are indeed very influential. Great-scale research has shown that the use of different commercial brands could factor into results, as suggested by Towheed et al. [31], in their meta-analysis of over 20 randomized controlled trials; only formulations of glucosamine sulfate manufactured by Rotta Laboratories displayed effectiveness in the symptomatic management of patients with OA of the knee, while with other presentations, no statistically significant results were obtained. 


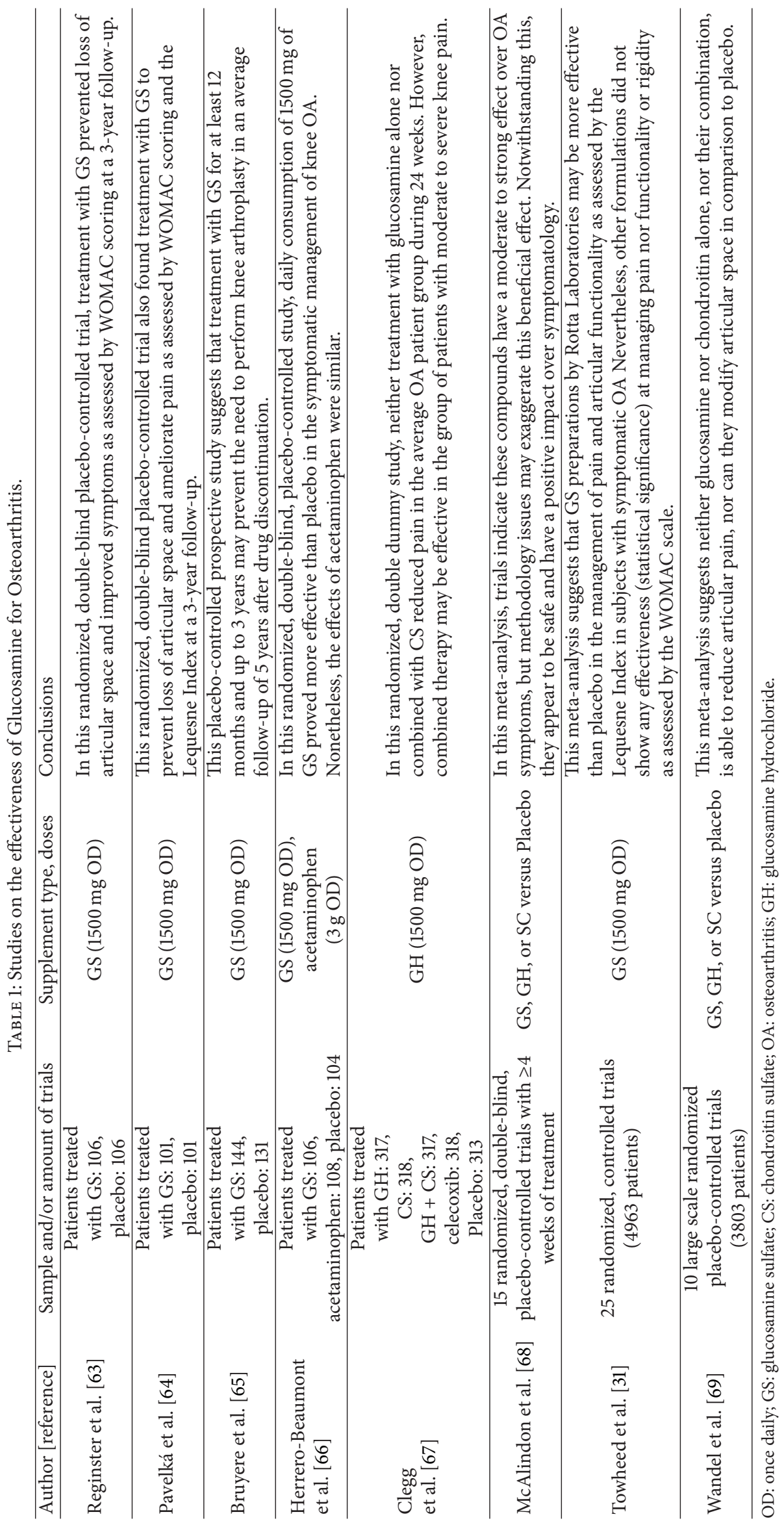


In addition to these findings, one of the most controversial reports surrounding the effectiveness of these supplements was issued by Wandel et al. [69], who in their meta-analysis of 10 large-scale randomized controlled trials (3,803 patients) concluded that neither glucosamine nor chondroitin sulfate, neither alone nor combined, could significantly improve pain nor reduction of articular space when compared to placebo, consequently arguing against prescribing these agents in patients with OA. This paper arose numerous criticisms from several specialists and experts in the matter [70,71], who fundamentally refuted the methodology used in their recollection and analysis of data, as well as their results, sustaining such claims by emphasizing the great variability and heterogeneity of the studies analyzed [58]. Notably, in the report of a post-publication meeting, the BMJ editor withdrew support from the inappropriate conclusions of this meta-nalysis, which were not adequately supported by their data. This illustrates the high degree of controversy attributed to the utilization of these compounds in patients with OA [60].

Although most studies tend to favor the effectiveness of these compounds in subjects with OA at least through minimal or indirect evidence, especially as disease-progression modulators [72], no evidence exists of chondroprotective effects of glucosamine in a preventive context [73]. This fits with the main findings of in vitro studies, which suggest a predominantly anticatabolic effect in cell cultures [74]. Several molecular mechanisms are implied, including the inhibition of catabolic enzymes, such as metalloproteases, phospholipase $A_{2}$, and aggrecanase- 2 as well as the rkversal of the effects of IL- $1 \beta$ and cyclooxigenase-2, and inhibition of NF- $\kappa$ B signaling [75-77]. This impact in energetic metabolism and oxidative stress appears to be triggered not only with the consumption of glucosamine alone, but also when accompanied with chondroitin sulfate [78]. These effects have been observed to be more consistent with glucosamine sulfate rather than hydrochloride [79].

Nevertheless, a great proportion of these experimental reports employ glucosamine concentrations much higher than those obtained through the oral ingestion of supplements, hindering the extrapolation of these findings to in vivo studies [80]. Regarding studies in animal models, findings are similar to in vitro results, with modifications predominantly in synovial inflammation, cartilage degradation, and bone resorption, primarily through the repression of proinflammatory cytokine genes [81]. Ultimately, the heterogeneity in experimental reports resembles its clinical counterpart, with important differences in the types of supplements used, as well as doses and other characteristics which should be unified in future studies. Harmonizing these criteria is a priority in order to accurately and successfully extrapolate molecular mechanisms to human subjects in the clinical scenario.

\section{Glucosamine: Safety on Glucose Metabolism}

Amidst the few adverse effects reported regarding glucosamine supplements [20], the most common are gastrointestinal complaints, including pain, diarrhea, nausea, and pyrosis [82]. On the other hand, although no fulminant events have been described, several cases of allergic reactions have been documented, including angioedema [83], asthmatic crises [84], and photosensitivity [85]. Lastly, much like the controversy surrounding their potential efficacy as therapeutic agents, the consequences of these supplements on carbohydrate metabolism and insulin levels have become one of the most debated topics in rheumatology in recent years [86].

The key point in this matter resides in several findings which associate the hexosamine pathway with the development of IR, with reports as early as the year 1991, when Marshall et al. [35] outlined such a hypothesis after exploring the role of glutamine in their experimental models for IR. As described previously, the final product of this metabolic pathway is UDP-N-Acetyl-GluN (Figure 4), which is precursor for GAG, proteoglycans and glycoproteins. It must be noted that these macromolecules are synthesized in specific cytoplasmic organelles (endoplasmic reticulum and Golgi apparatus) [87], while in the nucleus and cytosol, UDP-N-Acetyl-GluN also serves as a substrate for the enzymatic action of O-N-AcetylGluN transferase (OGT), which is able to transfer N-AcetylGluN to the serine/threonine residues of various proteins in a process known as reversible posttranslational proteic modification [88]. The target proteins of this process include the insulin receptor substrate (IRS) types 1 and 2, as well as GLUT-4 $[89,90]$. Numerous research groups suggest, albeit not in a definitive way, that these modifications may represent the molecular basis for IR associated with the hexosamine pathway [87], since it may antagonize the phosphorylation cascade of insulin signaling $[42,90]$.

Besides these cytosolic mechanisms, O-GluNacylation may also target many transcription factors, therefore regulating the expression of proteins in the nucleus [91, 92]. Several transcription factors have been shown to be involved through experimental models as well as genes such as those of glucose6-phosphatase and phosphoenolpyruvate carboxykinase, key enzymes from the gluconeogenesis pathway [93]. Thus, a great proportion of current research is focused on the role played by OGT in post-translational modifications, as its effects do not seem to be limited to insulin signalingacting as "metabosensor" mechanism-and it may be part of a wide array of alarm responses or stress reactions in the cardiovascular system [39, 94-96].

Despite these findings in animal models, reports in humans stand divided and although some research suggests metabolic effects for these supplements [50, 104], most clinical trials and meta-analyses suggest this link is not as much clear in humans (Table 2). Moreover, a great part of these studies-including clinical assays $[100,101]$ and metaanalyses $[102,103]$ - were carried out on subjects with already impaired glucose metabolism, obscuring the interpretation of their results. Nevertheless, several studies have failed to find associations between GluN administration and insulin resistance as assessed by its gold standard test, the euglycemic insulin clamp (EIC). Such is the case of Monauni et al., with their study on 10 healthy subjects who were assessed through determination of glycemia, application of glucose tolerance test, and the EIC while undergoing glucosamine 


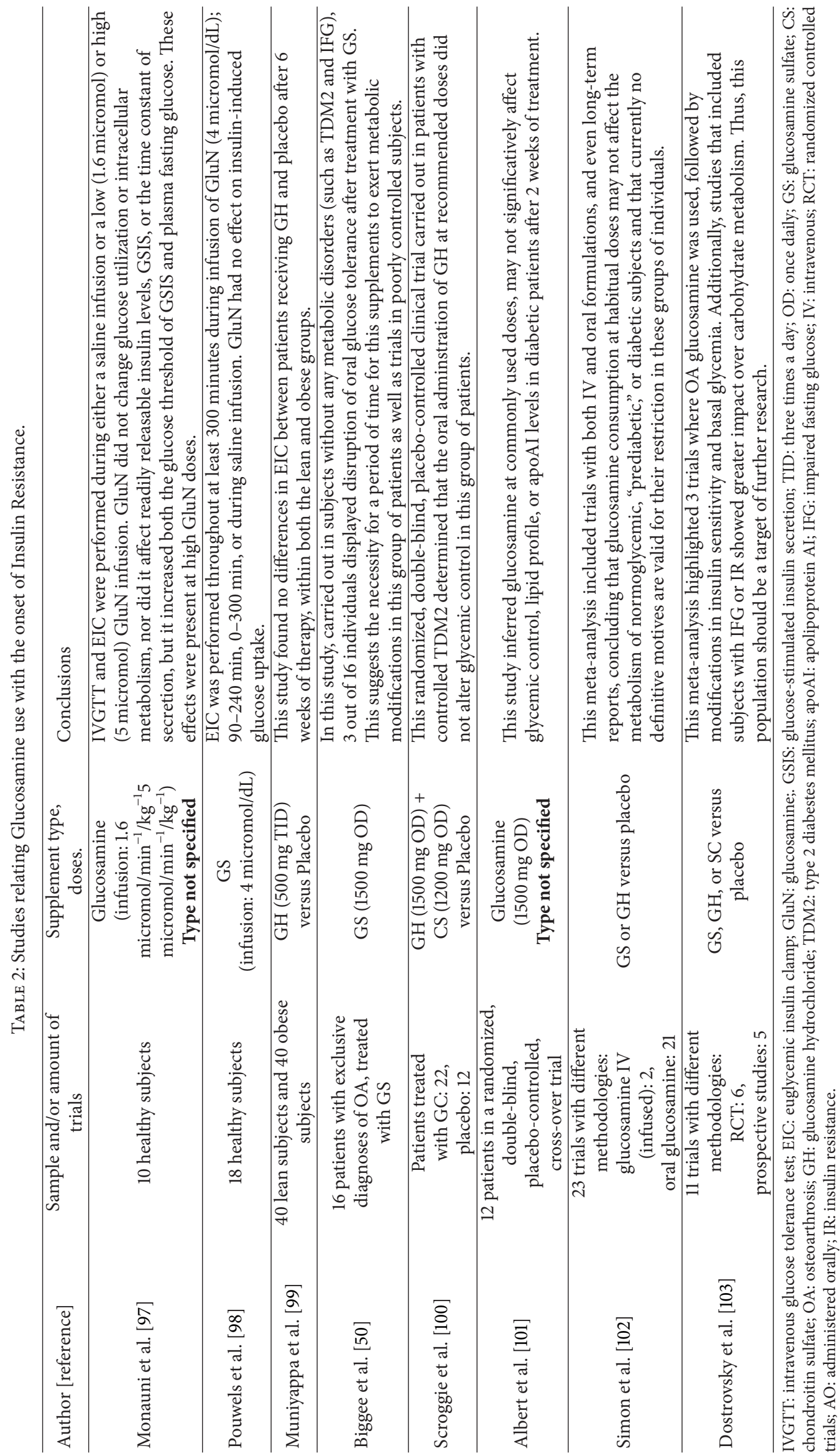


infusion [97]. Similar results were obtained in 18 healthy individuals with the double forearm technique [98], and no differences in IR nor endothelial dysfunction were evidenced by Muniyappa et al. between 20 lean subjects and 20 obese subjects after short- and long-term (6-week) administration of glucosamine [99].

Certain key points should be noted. Studies discrediting these effects base their conclusions in the magnitude of the required dosage for alterations on carbohydrate metabolism to occur, which must be over 100 times higher than the dose recommended for the management of OA [34]. In addition, long-term studies remain scarce, and current clinical trials suffer from certain methodology errors. Notably, future analyses should categorize and contrast their subjects according to consumption of hypoglycemic drugs and glycemic status, particularly if impaired fasting glucose is present [105]. However, dos Reis et al. [106] have highlighted the safety of crystalline GS regarding not only glucose metabolism but also lipid profile and blood pressure in cohorts from the GUIDE trial and the study by Reginster et al. [63], at follow-ups of 6 months and 3 years, respectively.

Ultimately, determining whether these supplements may influence the metabolism of carbohydrates and insulin secretion in humans should be an imperative objective in the field of diabetology, particularly in the face of recent findings linking glucosamine with endoplasmic reticulum stress [107, 108], a process that under hyperglycemic conditions could trigger a series of deleterious events, including expression of proinflammatory genes, proapoptotic signaling, and lipidic accumulation, which would lead to accelerated atherosclerosis and hepatic steatosis, implying a greater risk for cardiovascular disease $[109,110]$, besides representing potential pathophysiologic mechanisms for other uncommon adverse events [111].

\section{Conclusions}

Due to the growing impact of $\mathrm{OA}$ as a chronic degenerative disease in public health economic systems and the lifestyle of patients, the search for novel therapeutic alternatives must represent a fundamental object for multidisciplinary research groups, including primary attention physicians, rheumatologists, orthopedists, and physiotherapists. Glucosamine supplements, which encompass several types of chemical components, have become a mainstay of OA therapeutic management due to their important structure-preserving and symptom-relieving effects, as well as their cost effectiveness and relatively innocuous adverse effect profiles. Indeed, evidence supporting diabetogenesis as a feasible complication of glucosamine supplement use is scarce, and to date, this association remains only theoretical possibility. Although further research is required to fully understand this relationship, glucosamine supplements have been more than sufficiently proven to display overtly beneficial risk-to-reward profiles, and they should remain fundamental components of OA therapy.

\section{Conflict of Interests}

The authors declare that there are no financial or other contractual agreements that might cause conflict of interests.

\section{Acknowledgment}

This work was supported by Research Grant N ${ }^{\circ}$ CC-0437-1021-09-10 from the Technological, Humanistic, and Scientific Development Council (CONDES), University of Zulia, and Research Grant N . FZ-0058-2007 from Fundacite-Zulia.

\section{References}

[1] A. Poley González, J. A. Ortega Blanco, M. Pedregal González et al., "Prevalencia de enfermedades osteoarticulares y consumo de recursos. Calidad de vida y dependencia en pacientes con artrosis," Semergen, vol. 37, no. 9, pp. 462-467, 2011.

[2] Guía Clínica, Tratamiento Médico en personas de 55 años y más con Artrosis de Cadera y/o rodilla, Leve o Moderada, Minsal, Santiago, Chile, 2007, http://web.minsal.cl/ portal/url/item/a01c4b10a7c5219ae04001011f017145.pdf.

[3] M. Comas, M. Sala, R. Roman et al., "Variaciones en la estimación de la prevalencia de artrosis de rodilla según los criterios diagnósticos utilizados en los estudios poblacionales," Gaceta Sanitaria, vol. 24, no. 1, pp. 28-32, 2010.

[4] Centro Nacional de Enfermedades Reumáticas, Venezuela, 2010, http://www.cner.org.ve/pdf/reporte_2010.pdf.

[5] "Guía de práctica clínica para el diagnóstico y tratamiento de la osteoartrosis de rodilla," Secretaria de Salud, Mexico City, México, 2008, http://www. cvsp.cucs.udg.mx/guias/TODAS/IMSS_079_08_OSTEOARTROSIS_RODILLA/IMSS_079_08_EyR.pdf.

[6] S. H. Hassanali and G. O. Oyoo, "Osteoarthritis: a look at pathophysiology and approach to new treatments: a review," East African Orthopaedic Journal, vol. 5, pp. 51-57, 2011.

[7] S. Glasson, "Identification of targets through histologic evaluation of osteoarthritis in knockout mice," Osteoarthritis Cartilage, vol. 13, supplement A, p. S3, 2005.

[8] "Annual nutrition industry overview," Nutrition Business Journal, vol. 10, pp. 6-7, 2005.

[9] F. Guilak, "Biomechanical factors in osteoarthritis," Best Practice and Research, vol. 25, no. 6, pp. 815-823, 2011.

[10] L. Pulsatelli, O. Addimanda, V. Brusi et al., "New findings in osteoarthritis pathogenesis: therapeutic implications," Therapeutic Advances in Chronic Disease, vol. 4, no. 1, pp. 23-43, 2013.

[11] A. C. Bay-Jensen, S. Hoegh-Madsen, E. Dam et al., "Which elements are involved in reversible and irreversible cartilage degradation in osteoarthritis?" Rheumatology International, vol. 30, no. 4, pp. 435-442, 2010.

[12] M. G. Ehrlich, H. J. Mankin, H. Jones et al., "Collagenase and collagenase inhibitors in osteoarthritic and normal human cartilage," Journal of Clinical Investigation, vol. 59, no. 2, pp. 226233, 1977 .

[13] L. C. Tetlow, D. J. Adlam, and D. E. Woolley, "Matrix metalloproteinase and proinflammatory cytokine production by chondrocytes of human osteoarthritic cartilage: associations with degenerative changes," Arthritis \& Rheumatology, vol. 44, pp. 585-594, 2001.

[14] J. P. Pelletier, J. Martel-Pelletier, and S. B. Abramson, "Osteoarthritis, an inflammatory disease. Potential implication 
for the selection of new therapeutic targets," Arthritis \& Rheumatology, vol. 44, pp. 1237-1247, 2001.

[15] J. P. Schroeppel, J. D. Crist, H. C. Anderson, and J. Wang, "Molecular regulation of articular chondrocyte function and its significance in osteoarthritis," Histology and Histopathology, vol. 26, no. 3, pp. 377-394, 2011.

[16] R. M. Aspden, B. A. A. Scheven, and J. D. Hutchison, "Osteoarthritis as a systemic disorder including stromal cell differentiation and lipid metabolism," The Lancet, vol. 357, no. 9262, pp. 1118-1120, 2001.

[17] W. B. van den Berg, "Osteoarthritis year 2010 in review: pathomechanisms," Osteoarthritis and Cartilage, vol. 19, no. 4, pp. 338-341, 2011.

[18] M. V. Goycochea, V. M. López, M. Colin-Marin et al., "Guía clínica en osteoartrosis de rodilla y cadera," Revista Médica del Instituto Mexicano del Seguro Social, vol. 41, suplement, pp. S99S107, 2003.

[19] The Royal Australian College of General Practitioners, Guideline for the Non-Surgical Management of Hip and Knee Osteoarthritis, 2009, http://www.nhmrc.gov.au/ ffiles_nhmrc/publications/attachments/cpll7-hip-knee-osteoarthritis.pdf.

[20] W. Zhang, R. W. Moskowitz, G. Nuki et al., "OARSI recommendations for the management of hip and knee osteoarthritis, part II: OARSI evidence-based, expert consensus guidelines," Osteoarthritis and Cartilage, vol. 16, no. 2, pp. 137-162, 2008.

[21] R. Christensen, E. M. Bartels, A. Astrup, and H. Bliddal, "Effect of weight reduction in obese patients diagnosed with knee osteoarthritis: a systematic review and meta-analysis," Annals of the Rheumatic Diseases, vol. 66, no. 4, pp. 433-439, 2007.

[22] T. P. Stitik, E. Altschuler, and P. M. Foye, "Pharmacotherapy of osteoarthritis," American Journal of Physical Medicine and Rehabilitation, vol. 85, supplement, no. 11, pp. S15-S28, 2006.

[23] K. M. Jordan, N. K. Arden, M. Doherty et al., "EULAR recommendations 2003: an evidence based approach to the management of knee osteoarthritis: report of a Task Force of the Standing Committee for International Clinical Studies Including Therapeutic Trials (ESCISIT)," Annals of the Rheumatic Diseases, vol. 62, no. 12, pp. 1145-1155, 2003.

[24] E. Mongil, I. Sánchez, F. Torre et al., "Fármacos de acción lenta (Sysadoa) en el tratamiento de la osteoartrosis," Revista de la Sociedad Española del Dolor, vol. 7, pp. 485-496, 2006.

[25] B. L. Kidd, R. M. Langford, T. Wodehouse et al., "Current approaches in the treatment of arthritic pain," Arthritis Research and Therapy, vol. 9, no. 3, article 214, 2007.

[26] Ministry of Health Singapore (MOH), "Clinical practice guidelines Osteoarthritis of the knee," 2007, http://www.moh.gov.sg/cpg.

[27] National Prescribing Service (NPS), "Analgesic choices in persistent pain. Prescribing Practice Review," 2006, http://www.nps.org.au/publications/health-professional/ prescribing-practice-review/2006/analgesic-choices-inpersistent-pain.

[28] E. M. Antman, J. S. Bennett, A. Daugherty, C. Furberg, H. Roberts, and K. A. Taubert, "Use of nonsteroidal antiinflammatory drugs: an update for clinicians: a scientific statement from the American Heart Association," Circulation, vol. 115, no. 12, pp. 1634-1642, 2007.

[29] S. Tanaka, C. Hamanishi, H. Kikuchi, and K. Fukuda, "Factors related to degradation of articular cartilage in osteoarthritis: a review," Seminars in Arthritis and Rheumatism, vol. 27, no. 6, pp. 392-399, 1998.
[30] F. J. Blanco, R. Guitian, E. Vazquez-Martul, F. J. de Toro, and F. Galdo, "Osteoarthritis chondrocytes die by apoptosis," Arthritis \& Rheumatology, vol. 41, pp. 284-289, 1998.

[31] T. E. Towheed, L. Maxwell, T. P. Anastassiades et al., "Glucosamine therapy for treating osteoarthritis," Cochrane Database of Systematic Reviews, no. 2, Article ID CD002946, 2005.

[32] S. C. Vlad, M. P. LaValley, T. E. McAlindon, and D. T. Felson, "Glucosamine for pain in osteoarthritis: why do trial results differ?” Arthritis and Rheumatism, vol. 56, no. 7, pp. 2267-2277, 2007.

[33] E. A. Heath-Heckman and M. J. McFall-Ngai, "The occurrence of chitin in the hemocytes of invertebrates," Zoology, vol. 114, no. 4, pp. 191-198, 2011.

[34] J. W. Anderson, R. J. Nicolosi, and J. F. Borzelleca, “Glucosamine effects in humans: a review of effects on glucose metabolism, side effects, safety considerations and efficacy," Food and Chemical Toxicology, vol. 43, no. 2, pp. 187-201, 2005.

[35] S. Marshall, V. Bacote, and R. R. Traxinger, "Discovery of a metabolic pathway mediating glucose-induced desensitization of the glucose transport system: role of hexosamine in the induction of insulin resistance," The Journal of Biological Chemistry, vol. 266, no. 8, pp. 4706-4712, 1991.

[36] R. Kornfeld, "Studies on L-glutamine D-fructose 6phosphate amidotransferase. I. Feedback inhibition by uridine diphosphate-N-acetylglucosamine," The Journal of Biological Chemistry, vol. 242, no. 13, pp. 3135-3141, 1967.

[37] G. Wu, T. E. Haynes, W. Yan, and C. J. Meininger, "Presence of glutamine:fructose-6-phosphate amidotransferase for glucosamine-6-phosphate synthesis in endothelial cells: effects of hyperglycaemia and glutamine," Diabetologia, vol. 44, no. 2 , pp. 196-202, 2001.

[38] M. Uldry, M. Ibberson, M. Hosokawa, and B. Thorens, "GLUT2 is a high affinity glucosamine transporter," FEBS Letters, vol. 524, no. 1-3, pp. 199-203, 2002.

[39] N. Fülöp, R. B. Marchase, and J. C. Chatham, "Role of protein $\mathrm{O}$-linked $\mathrm{N}$-acetyl-glucosamine in mediating cell function and survival in the cardiovascular system," Cardiovascular Research, vol. 73, no. 2, pp. 288-297, 2007.

[40] E. D. Schleicher and C. Weigert, "Role of the hexosamine biosynthetic pathway in diabetic nephropathy," Kidney International, Supplement, vol. 58, supplement 77, pp. S13-S18, 2000.

[41] G. D. Holt and G. W. Hart, "The subcellular distribution of terminal N-acetylglucosamine moieties. Localization of a novel protein-saccharidie linkage, O-linked GlcNAc," The Journal of Biological Chemistry, vol. 261, no. 17, pp. 8049-8057, 1986.

[42] R. J. Copeland, J. W. Bullen, and G. W. Hart, "Cross-talk between GlcNAcylation and phosphorylation: roles in insulin resistance and glucose toxicity," American Journal of PhysiologyEndocrinology and Metabolism, vol. 295, no. 1, pp. E17-E28, 2008.

[43] W. B. Dias and G. W. Hart, "O-GlcNAc modification in diabetes and Alzheimer's disease," Molecular BioSystems, vol. 3, no. 11, pp. 766-772, 2007.

[44] S. Milewski, "Glucosamine-6-phosphate synthase: the multifacets enzyme," Biochimica et Biophysica Acta, vol. 1597, no. 2, pp. 173-192, 2002.

[45] G. L. McKnight, S. L. Mudri, S. L. Mathewes et al., "Molecular cloning, cDNA sequence, and bacterial expression of human glutamine: fructose-6-phosphate amidotransferase," The Journal of Biological Chemistry, vol. 267, no. 35, pp. 25208-25212, 1992. 
[46] P. P. Sayeski and J. E. Kudlow, "Glucose metabolism to glucosamine is necessary for glucose stimulation of transforming growth factor- $\alpha$ gene transcription," The Journal of Biological Chemistry, vol. 271, no. 25, pp. 15237-15243, 1996.

[47] J. Zhou, Q. K. Huynh, R. T. Hoffman et al., "Regulation of glutamine: fructose-6-phosphate amidotransferase by cAMPdependent protein kinase," Diabetes, vol. 47, no. 12, pp. 1836$1840,1998$.

[48] M. J. Pouwels, J. R. Jacobs, P. N. Span, J. A. Lutterman, P. Smits, and C. J. Tack, "Short-term glucosamine infusion does not affect insulin sensitivity in humans," Journal of Clinical Endocrinology and Metabolism, vol. 86, no. 5, pp. 2099-2103, 2001.

[49] I. Setnikar and L. C. Rovati, "Absorption, distribution, metabolism and excretion of glucosamine sulfate: a review," Arzneimittel-Forschung/Drug Research, vol. 51, no. 9, pp. 699-725, 2001.

[50] B. A. Biggee, C. M. Blinn, M. Nuite, J. E. Silbert, and T. E. McAlindon, "Effects of oral glucosamine sulphate on serum glucose and insulin during an oral glucose tolerance test of subjects with osteoarthritis," Annals of the Rheumatic Diseases, vol. 66, no. 2, pp. 260-262, 2007.

[51] A. Aghazadeh-Habashi, S. Sattari, F. Pasutto, and F. Jamali, "Single dose pharmacokinetics and bioavailability of glucosamine in the rat," Journal of Pharmacy and Pharmaceutical Sciences, vol. 5, no. 2, pp. 181-184, 2002.

[52] T. Pham, D. V. der Heijde, M. Lassere et al., "Outcome variables for osteoarthritis clinical trials: the OMERACT-OARSI set of responder criteria," Journal of Rheumatology, vol. 30, no. 7, pp. 1648-1654, 2003.

[53] N. Bellamy, W. W. Buchanan, C. H. Goldsmith, J. Campbell, and L. W. Stitt, "Validation study of WOMAC: a health status instrument for measuring clinically important patient relevant outcomes to antirheumatic drug therapy in patients with osteoarthritis of the hip or knee," Journal of Rheumatology, vol. 15, no. 12, pp. 1833-1840, 1988.

[54] M. Dougados, "Monitoring osteoarthritis progression and therapy," Osteoarthritis and Cartilage, vol. 12, supplement A, pp. S55-S60, 2004.

[55] M. J. Divins, “Mercado de antiartrósicos," Farmacia Profesional, vol. 24, no. 1, pp. 40-44, 2010.

[56] E. J. Uitterlinden, H. Jahr, J. L. M. Koevoet et al., "Glucosamine decreases expression of anabolic and catabolic genes in human osteoarthritic cartilage explants," Osteoarthritis and Cartilage, vol. 14, no. 3, pp. 250-257, 2006.

[57] L. C. Rovati, F. Girolami, and S. Persiani, "Crystalline glucosamine sulfate in the management of knee osteoarthritis: efficacy, safety, and pharmacokinetic properties," Therapeutic Advances in Musculoskeletal Disease, vol. 4, no. 3, pp. 167-180, 2012.

[58] R. Calvo, "Sulfato de glucosamina y condroitín sulfato, fármacos para el tratamiento de la artrosis, acusados de no presentar eficacia clínica. ¿Culpables?” Gaceta Médica de Bilbao, vol. 109, no. 4, pp. 158-164, 2012.

[59] C. Black, C. Clar, R. Henderson et al., "The clinical effectiveness of glucosamine and chondroitin supplements in slowing or arresting progression of osteoarthritis of the knee: a systematic review and economic evaluation," Health Technology Assessment, vol. 13, no. 52, pp. 1-123, 2009.

[60] Sociedad Uruguaya de Reumatología (SUR), "Utilidad de los antiartrósicos de acción lenta en el tratamiento de la artrosis," Carta Reumatológica, vol. 3, no. 1, pp. 1-40, 2012, http://www.reumauruguay.org/web/images/carta_reumatologica_2012.pdf.

[61] F. Abad Santos, D. Ochoa, and A. García García, "Actualización de la eficacia de condroitín sulfato y sulfato de glucosamina en el tratamiento de la artrosis," Actualidad en farmacología y terapéutica, vol. 9, pp. 97-108, 2011.

[62] P. Tugwell, M. Boers, P. Brooks, L. Simon, V. Strand, and L. Idzerda, "OMERACT: an international initiative to improve outcome measurement in rheumatology," Trials, vol. 8, article 38, 2007.

[63] J. Y. Reginster, R. Deroisy, L. C. Rovati et al., "Long-term effects of glucosamine sulphate on osteoarthritis progression: a randomised, placebo-controlled clinical trial," The Lancet, vol. 357, no. 9252, pp. 251-256, 2001.

[64] K. Pavelká, J. Gatterová, M. Olejarová, S. Machacek, G. Giacovelli, and L. C. Rovati, "Glucosamine sulfate use and delay of progression of knee osteoarthritis: a 3-year, randomized, placebo-controlled, double-blind study," Archives of Internal Medicine, vol. 162, no. 18, pp. 2113-2123, 2002.

[65] O. Bruyere, K. Pavelka, L. C. Rovati et al., "Total joint replacement after glucosamine sulphate treatment in knee osteoarthritis: results of a mean 8-year observation of patients from two previous 3-year, randomised, placebo-controlled trials," Osteoarthritis and Cartilage, vol. 16, no. 2, pp. 254-260, 2008.

[66] G. Herrero-Beaumont, J. A. Román Ivorra, M. D. C. Trabado et al., "Glucosamine sulfate in the treatment of knee osteoarthritis symptoms: a randomized, double-blind, placebo-controlled study using acetaminophen as a side comparator," Arthritis and Rheumatism, vol. 56, no. 2, pp. 555-567, 2007.

[67] D. O. Clegg, D. J. Reda, C. L. Harris et al., "Glucosamine, chondroitin sulfate, and the two in combination for painful knee osteoarthritis," The New England Journal of Medicine, vol. 354, no. 8, pp. 795-808, 2006.

[68] T. E. McAlindon, M. P. La Valley, J. P. Gulin, and D. T. Felson, "Glucosamine and chondroitin for treatment of osteoarthritis: a systematic quality assessment and meta-analysis," Journal of the American Medical Association, vol. 283, no. 11, pp. 1469-1475, 2000.

[69] S. Wandel, P. Jüni, B. Tendal et al., "Effects of glucosamine, chondroitin, or placebo in patients with osteoarthritis of hip or knee: network meta-analysis," British Medical Journal, vol. 341, Article ID c4675, 2010.

[70] G. Giacovelli and L. C. Rovati, "Glucosamine and osteoarthritis. Conclusions not supported by methods and results," British Medical Journal, vol. 341, Article ID c6338, 2010.

[71] J. Reginster, R. D. Altman, and M. C. Hochberg, "Glucosamine and osteoarthritis. Prescribed regimen is effective," British Medical Journal, vol. 341, Article ID c6335, 2010.

[72] J. Reginster, A. Neuprez, M. Lecart, N. Sarlet, and O. Bruyere, "Role of glucosamine in the treatment for osteoarthritis," Rheumatology International, vol. 32, no. 10, pp. 2959-2967, 2012.

[73] Y. Herontin, X. Chevalier, G. Herrero-Beaumont et al., "Physiological effects of oral glucosamine on joint health: current status and consensus on future research priorities," BMC Research Notes, vol. 6, article 115, 2013.

[74] Y. Henrotin, A. Mobasheri, and M. Marty, "Is there any scientific evidence for the use of glucosamine in the management of human osteoarthritis?" Arthritis Research and Therapy, vol. 14, no. 1, article 201, 2012.

[75] K. Imagawa, M. C. de Andrés, K. Hashimoto et al., "The epigenetic effect of glucosamine and a nuclear factor-kappa B (NF$\mathrm{kB}$ ) inhibitor on primary human chondrocytes-implications 
for osteoarthritis," Biochemical and Biophysical Research Communications, vol. 405, no. 3, pp. 362-367, 2011.

[76] A. R. Shikhman, K. Kuhn, N. Alaaeddine, and M. Lotz, "N-acetylglucosamine prevents IL- $1 \beta$-mediated activation of human chondrocytes," Journal of Immunology, vol. 166, no. 8, pp. 5155-5160, 2001.

[77] M. B. Goldring and M. Otero, "Inflammation in osteoarthritis," Current Opinion in Rheumatology, vol. 23, no. 5, pp. 471-478, 2011.

[78] P. Chan, J. P. Caron, and M. W. Orth, "Short-term gene expression changes in cartilage explants stimulated with interleukin $1 \beta$ plus glucosamine and chondroitin sulfate," Journal of Rheumatology, vol. 33, no. 7, pp. 1329-1340, 2006.

[79] V. Calamia, C. Ruiz-Romero, B. Rocha et al., "Pharmacoproteomic study of the effects of chondroitin and glucosamine sulfate on human articular chondrocytes," Arthritis Research and Therapy, vol. 12, no. 4, article R138, 2010.

[80] B. A. Biggee, C. M. Blinn, T. E. McAlindon, M. Nuite, and J. E. Silbert, "Low levels of human serum glucosamine after ingestion of glucosamine sulphate relative to capability for peripheral effectiveness," Annals of the Rheumatic Diseases, vol. 65, no. 2, pp. 222-226, 2006.

[81] N. Ivanovska and P. Dimitrova, "Bone resorption and remodeling in murine collagenase-induced osteoarthritis after administration of glucosamine," Arthritis Research and Therapy, vol. 13, no. 2, article R44, 2011.

[82] E. C. Huskisson, "Glucosamine and chondroitin for osteoarthritis," Journal of International Medical Research, vol. 36, no. 6, pp. 1161-1179, 2008.

[83] V. Matheu, M. T. Gracia Bara, R. Pelta, E. Vivas, and M. Rubio, "Immediate-hypersensitivity reaction to glucosamine sulfate," Allergy, vol. 54, no. 6, p. 643, 1999.

[84] A. F. Tallia and D. A. Cardone, "Asthma exacerbation associated with glucosamine-chondroitin supplement," Journal of the American Board of Family Practice, vol. 15, no. 6, pp. 481-484, 2002.

[85] T. Danao-Camara, "Potential side effects of treatment with glucosamine and chondroitin," Arthritis and Rheumatism, vol. 43 , no. 12 , p. $2853,2000$.

[86] J. J. Manson and A. Rahman, "This house believes that we should advise our patients with osteoarthritis of the knee to take glucosamine," Rheumatology, vol. 43, no. 1, pp. 100-101, 2004.

[87] M. G. Buse, "Hexosamines, insulin resistance, and the complications of diabetes: current status," American Journal of Physiology_Endocrinology and Metabolism, vol. 290, no. 1, pp. E1-E8, 2006.

[88] W. A. Lubas, D. W. Frank, M. Krause, and J. A. Hanover, "Olinked GlcNAc transferase is a conserved nucleocytoplasmic protein containing tetratricopeptide repeats," The Journal of Biological Chemistry, vol. 272, no. 14, pp. 9316-9324, 1997.

[89] F. Andreozzi, C. D’Alessandris, M. Federici et al., "Activation of the hexosamine pathway leads to phosphorylation of insulin receptor substrate-1 on Ser307 and Ser612 and impairs the phosphatidylinositol 3-kinase/akt/mammalian target of rapamycin insulin biosynthetic pathway in RIN pancreatic $\beta$ cells," Endocrinology, vol. 145, no. 6, pp. 2845-2857, 2004.

[90] M. G. Buse, K. A. Robinson, B. A. Marshall, R. C. Hresko, and M. M. Mueckler, "Enhanced O-GlcNAc protein modification is associated with insulin resistance in GLUT1-overexpressing muscles," American Journal of Physiology-Endocrinology and Metabolism, vol. 283, no. 2, pp. E241-E250, 2002.
[91] X. Yang, K. Su, M. D. Roos, Q. Chang, A. J. Paterson, and J. E. Kudlow, "O-linkage of $\mathrm{N}$-acetylglucosamine to Sp1 activation domain inhibits its transcriptional capability," Proceedings of the National Academy of Sciences of the United States of America, vol. 98, no. 12, pp. 6611-6616, 2001.

[92] N. Lamarre-Vincent and L. C. Hsieh-Wilson, "Dynamic glycosylation of the transcription factor CREB: a potential role in gene regulation," Journal of the American Chemical Society, vol. 125, no. 22, pp. 6612-6613, 2003.

[93] M. P. Housley, N. D. Udeshi, J. T. Rodgers et al., "A PGC-1 $\alpha$ O-GlcNAc transferase complex regulates FoxO transcription factor activity in response to glucose," The Journal of Biological Chemistry, vol. 284, no. 8, pp. 5148-5157, 2009.

[94] B. Laczy, B. G. Hill, K. Wang et al., "Protein O-GlcNAcylation: a new signaling paradigm for the cardiovascular system," American Journal of Physiology-Heart and Circulatory Physiology, vol. 296, no. 1, pp. H13-H28, 2009.

[95] G. A. Ngoh, H. T. Facundo, A. Zafir, and S. P. Jones, "O-GlcNAc signaling in the cardiovascular system," Circulation Research, vol. 107, no. 2, pp. 171-185, 2010.

[96] V. V. Lima, K. Spitler, H. Choi, R. C. Webb, and R. C. Tostes, "O-GlcNAcylation and oxidation of proteins: is signalling in the cardiovascular system becoming sweeter?" Clinical Science, vol. 123, no. 8, pp. 473-486, 2012.

[97] T. Monauni, M. G. Zenti, A. Cretti et al., "Effects of glucosamine infusion on insulin secretion and insulin action in humans," Diabetes, vol. 49, no. 6, pp. 926-935, 2000.

[98] J. L. Stumpf and S. W. Lin, "Effect of glucosamine on glucose control," Annals of Pharmacotherapy, vol. 40, no. 4, pp. 694-698, 2006.

[99] R. Muniyappa, R. J. Karne, G. Hall et al., "Oral glucosamine for 6 weeks at standard doses does not cause or worsen insulin resistance or endothelial dysfunction in lean or obese subjects," Diabetes, vol. 55, no. 11, pp. 3142-3150, 2006.

[100] D. A. Scroggie, A. Albright, and M. D. Harris, "The effect of glucosamine-chondroitin supplementation on glycosylated hemoglobin levels in patients with type 2 diabetes mellitus: a placebo-controlled, double-blinded, randomized clinical trial," Archives of Internal Medicine, vol. 163, no. 13, pp. 1587-1590, 2003.

[101] S. G. Albert, R. F. Oiknine, S. Parseghian, A. D. Mooradian, M. J. Haas, and T. McPherson, "The effect of glucosamine on serum HDL cholesterol and apolipoprotein AI levels in people with diabetes," Diabetes Care, vol. 30, no. 11, pp. 2800-2803, 2007.

[102] R. R. Simon, V. Marks, A. R. Leeds, and J. W. Anderson, "A comprehensive review of oral glucosamine use and effects on glucose metabolism in normal and diabetic individuals," Diabetes/Metabolism Research and Reviews, vol. 27, no. 1, pp. 1427, 2011.

[103] N. R. Dostrovsky, T. E. Towheed, R. W. Hudson, and T. P. Anastassiades, "The effect of glucosamine on glucose metabolism in humans: a systematic review of the literature," Osteoarthritis and Cartilage, vol. 19, no. 4, pp. 375-380, 2011.

[104] T. Pham, A. Cornea, K. E. Blick, A. Jenkins, and R. H. Scofield, "Oral glucosamine in doses used to treat osteoarthritis worsens insulin resistance," American Journal of the Medical Sciences, vol. 333, no. 6, pp. 333-339, 2007.

[105] P. D. Marshall, S. Poddar, and E. M. Tweed, "Clinical inquiries: do glucosamine and chondroitin worsen blood sugar control in diabetes?" Journal of Family Practice, vol. 55, no. 12, pp. 10911093, 2006. 
[106] R. P. dos Reis, G. Giacovelli, F. Girolami, R. André, A. Bonazzi, and L. C. Rovati, "Crystalline glucosamine sulfate in the treatment of osteoarthritis: evidence of long-term cardiovascular safety from clinical trials," Open Rheumatology Journal, vol. 5, no. 1, pp. 69-77, 2011.

[107] G. A. Raciti, C. Iadicicco, L. Ulianich et al., "Glucosamineinduced endoplasmic reticulum stress affects GLUT4 expression via activating transcription factor 6 in rat and human skeletal muscle cells," Diabetologia, vol. 53, no. 5, pp. 955-965, 2010.

[108] A. T. Sage, L. A. Walter, Y. Shi et al., "Hexosamine biosynthesis pathway flux promotes endoplasmic reticulum stress, lipid accumulation, and inflammatory gene expression in hepatic cells," American Journal of Physiology-Endocrinology and Metabolism, vol. 298, no. 3, pp. E499-E511, 2010.

[109] D. R. Beriault, S. Sharma, Y. Shi, M. I. Khan, and G. H. Werstuck, "Glucosamine-supplementation promotes endoplasmic reticulum stress, hepatic steatosis and accelerated atherogenesis in apoE-/- mice," Atherosclerosis, vol. 219, no. 1, pp. 134-140, 2011.

[110] D. R. Beriault and G. H. Werstuck, "The role of glucosamineinduced ER stress in diabetic atherogenesis," Experimental Diabetes Research, vol. 2012, Article ID 187018, 11 pages, 2012.

[111] V. Ebrahim, M. Albeldawi, and D. J. Chiang, "Acute liver injury associated with glucosamine dietary supplement," BMJ Case Reports, 2012. 


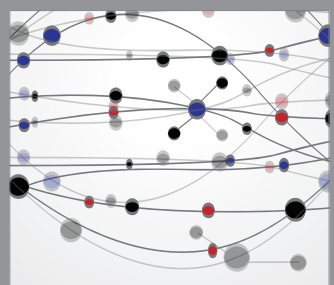

The Scientific World Journal
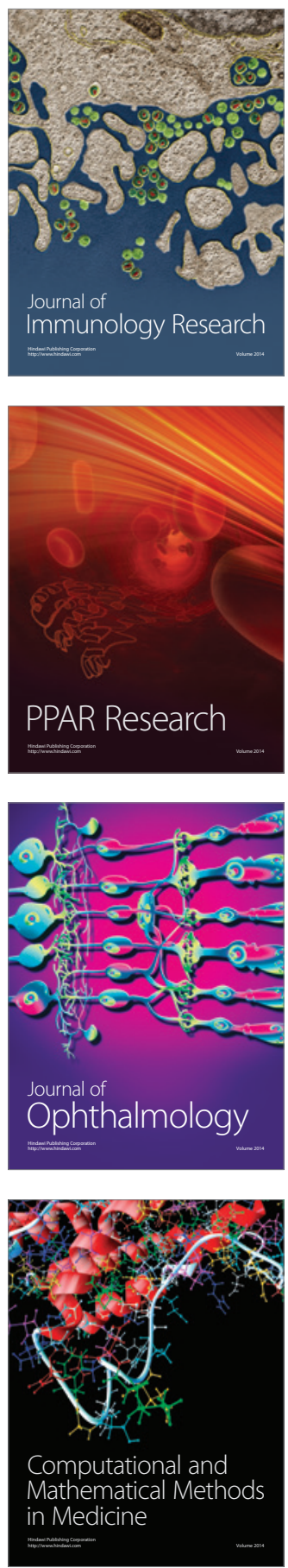

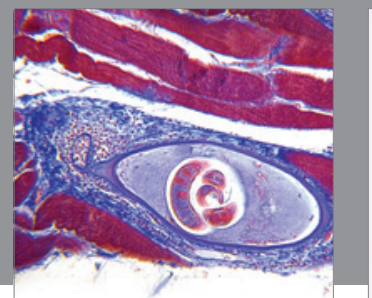

Gastroenterology

Research and Practice
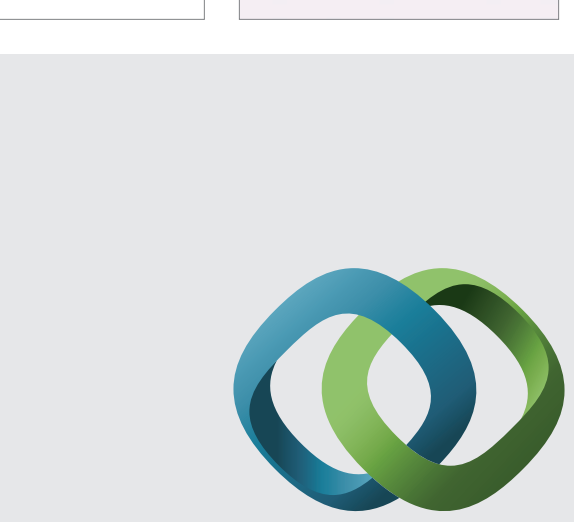

\section{Hindawi}

Submit your manuscripts at

http://www.hindawi.com
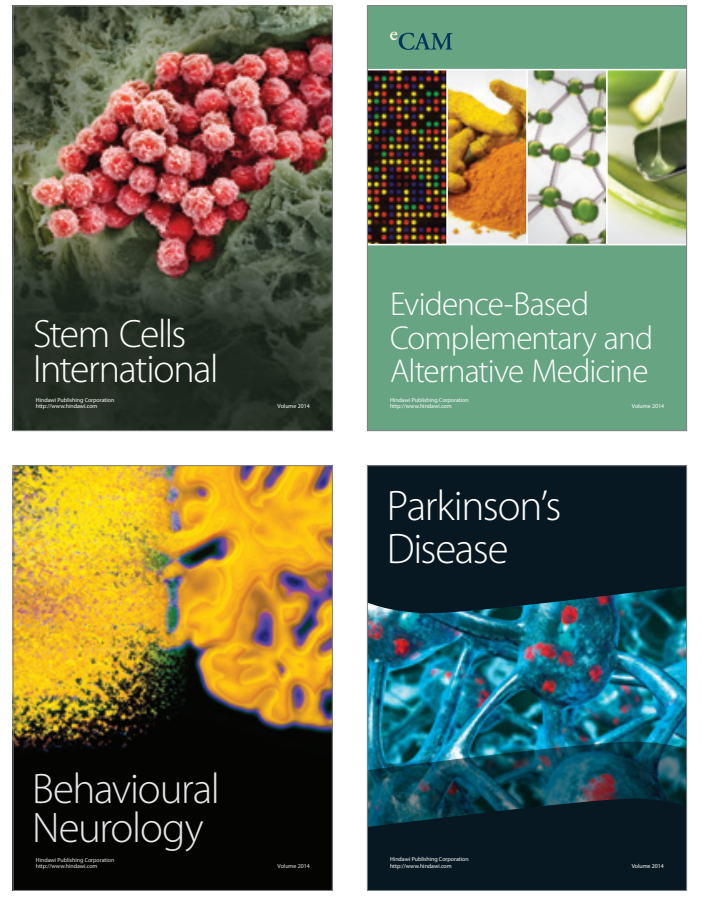
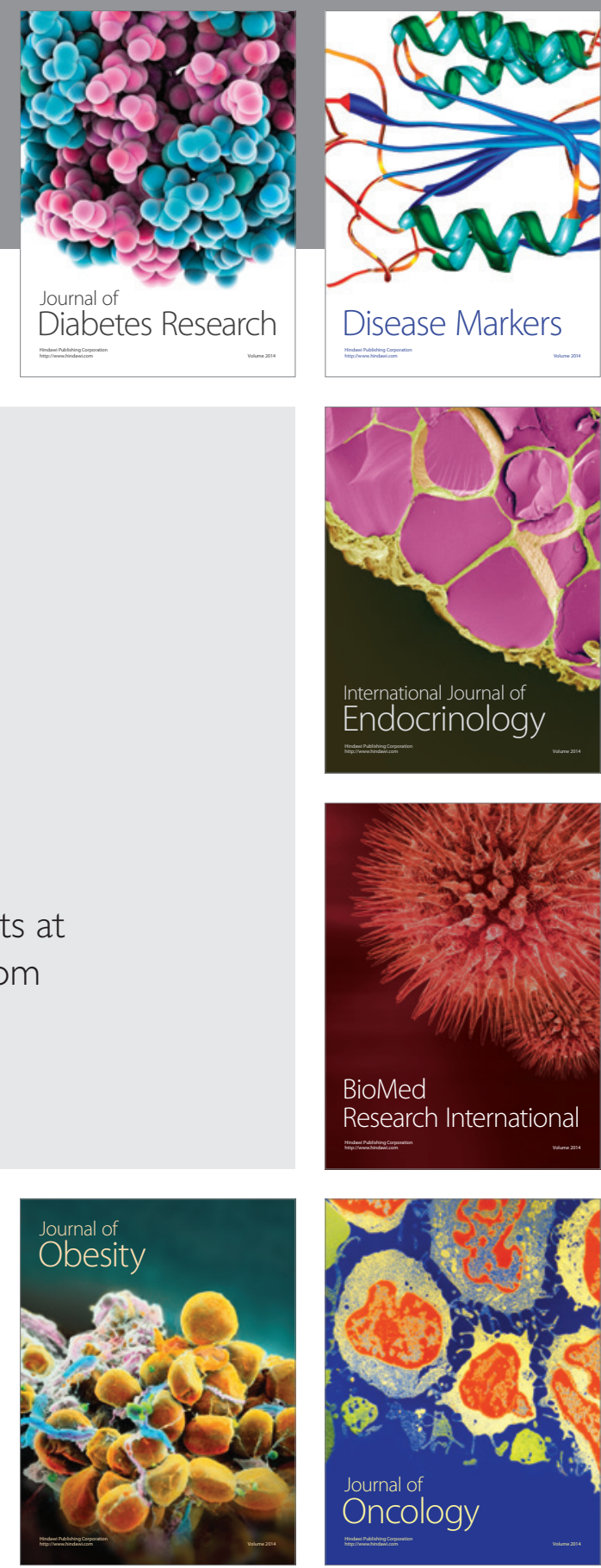

Disease Markers
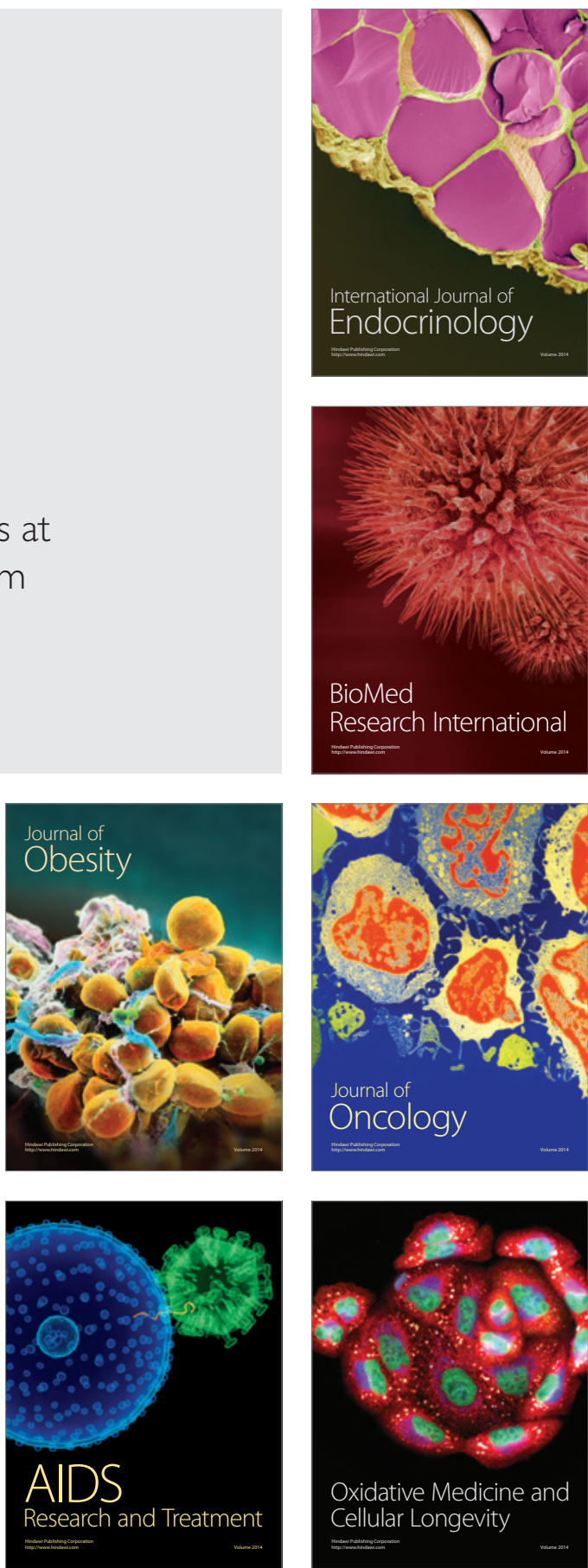